Supporting Information

\title{
Cellular Uptake of a Fluorescent Calix[4]arene Derivative
}

\author{
Ruth Lalor, ${ }^{1}$ Hugo Baillie-Johnson, ${ }^{2}$ Carl Redshaw, ${ }^{1}$ Susan. E. Matthews*, ${ }^{1}$ Anja Mueller*1 \\ ${ }^{1}$ School of Chemical Sciences and Pharmacy, University of East Anglia, Norwich, NR4 7TJ, UK. \\ ${ }^{2}$ Department of Oncology, Norwich and Norfolk University Hospital, Norwich, NR4 7UY \\ susan.matthews@uea.ac.uk, anja.mueller@uea.ac.uk
}

\section{Experimental Procedures}

Chemical Syntheses Compound 3 To a stirring solution of 5,11,17,23-tetra-Boc-amino-25,26,27tripropoxy-28-aminopropoxycalix[4] $\operatorname{arene}^{1}(0.15 \mathrm{~g}, 0.14 \mathrm{mmol})$ in EtOAc $(3 \mathrm{~mL})$ was added 4-chloro7-nitrobenzofurazan (NBD chloride) $(0.042 \mathrm{~g}, 0.21 \mathrm{mmol})$, and the resultant solution heated at $60{ }^{\circ} \mathrm{C}$ for $4 \mathrm{~h}$. Water $(3 \mathrm{~mL})$ and dichloromethane $(5 \mathrm{~mL})$ were added, the organic phase separated, washed with $\mathrm{HCl}(10 \%), \mathrm{NaOH}(10 \%)$ and brine, and the solvent removed under reduced pressure. The residue was purified over column chromatography, eluting with a gradient of hexane : dichloromethane (1:1) to dichloromethane to dichloromethane : EtOAc (19:1), yielding the product 3 as an orange solid $(0.05 \mathrm{~g}, 30 \%)$. IR $v \mathrm{NH}=3315 \mathrm{~cm}^{-1}, v \mathrm{NO}_{2}=1698 \mathrm{~cm}^{-1}, v \mathrm{NH}=1593 \mathrm{~cm}^{-1} ;{ }^{1} \mathbf{H}$ NMR $\left(400 \mathrm{MHz}, \mathrm{CDCl}_{3}\right)$; $8.47\left(1 \mathrm{H}, \mathrm{d}, J=8.5 \mathrm{~Hz}, \operatorname{Ar}_{\mathrm{NBD}} H\right), 6.75(3 \mathrm{H}, \mathrm{b} \mathrm{s}, \operatorname{ArH}), 6.54(3 \mathrm{H}, \mathrm{m}, \operatorname{ArH}), 6.29(1 \mathrm{H}, \mathrm{s}, \operatorname{ArH}), 6.27(1 \mathrm{H}$, $\mathrm{s}, \operatorname{ArH}), 6.10\left(1 \mathrm{H}, \mathrm{d}, J=8.5 \mathrm{~Hz}, \operatorname{Ar}_{\mathrm{NBD}} H\right), 4.34\left(2 \mathrm{H}, \mathrm{d}, J=13.3 \mathrm{~Hz}, \mathrm{ArCH}_{2} \mathrm{Ar}\right), 4.29(2 \mathrm{H}, \mathrm{d}, J=13.3$ $\left.\mathrm{Hz}, \mathrm{ArCH} \mathrm{Ar}_{2}\right), 4.05\left(2 \mathrm{H}, \mathrm{t}, J=6.1 \mathrm{~Hz}, \mathrm{OCH}_{2} \mathrm{CH}_{2} \mathrm{CH}_{2} \mathrm{~N}\right), 3.81-3.62\left(8 \mathrm{H}, \mathrm{m}, \mathrm{OCH}_{2} \mathrm{CH}_{2} \mathrm{CH}_{3}\right.$, $\mathrm{OCH}_{2} \mathrm{CH}_{2} \mathrm{CH}_{2} \mathrm{NH}_{2}$, coincident), $3.12\left(2 \mathrm{H}, \mathrm{d}, J=13.3 \mathrm{~Hz}, \mathrm{ArCH} \mathrm{H}_{2} \mathrm{Ar}\right), 3.09(2 \mathrm{H}, \mathrm{d}, J=13.3 \mathrm{~Hz}$, $\left.\mathrm{ArCH} \mathrm{H}_{2} \mathrm{Ar}\right), 2.36\left(2 \mathrm{H}, \mathrm{m}, \mathrm{OCH}_{2} \mathrm{CH}_{2} \mathrm{CH}_{2} \mathrm{~N}\right), 1.83\left(6 \mathrm{H}, \mathrm{m}, \mathrm{OCH}_{2} \mathrm{CH}_{2} \mathrm{CH}_{3}\right), 1.50\left(18 \mathrm{H}, \mathrm{s}, \mathrm{C}\left(\mathrm{CH}_{3}\right)_{3}\right), 1.46$ $\left(18 \mathrm{H}, \mathrm{s}, \mathrm{C}\left(\mathrm{CH}_{3}\right)_{3}\right), 0.93(9 \mathrm{H}, \mathrm{m}$,

$\left.\mathrm{OCH}_{2} \mathrm{CH}_{2} \mathrm{CH}_{3}\right) ;{ }^{13} \mathrm{C}$ NMR $\left(100 \mathrm{MHz} ; \mathrm{CDCl}_{3}\right) ; 155.63,153.7,153.6,153.5,136.6,136.5,135.7,134.5$, $132.3,120.4,120.3,120.2,120.1,119.9,80.3,77.1,71.4,60.6,31.4,31.3,31.2,29.4,28.6,23.5,23.2$, $10.7,10.6 ; \mathbf{M} / \mathbf{z}$ (ESI) $1248\left[\mathrm{M}+\mathrm{NH}_{4}\right]^{+}$

Compound $4 \mathrm{HCl}_{(\mathrm{g})}$ was bubbled for $15 \mathrm{~min}$ through a stirring solution of $3(0.05 \mathrm{~g}, 0.04 \mathrm{mmol})$ in dichloromethane $(3 \mathrm{~mL})$, after which time a precipitate formed. Bubbling of $\mathrm{HCl}_{(\mathrm{g})}$ was continued for a further $10 \mathrm{~min}$. to ensure complete deprotection. The solvent was removed under reduced pressure, yielding 4 as a dark red solid (quantitative). IR $v \mathrm{NH}=3375 \mathrm{~cm}^{-1}, 3180 \mathrm{~cm}^{-1}, v \mathrm{NO}_{2}=1616 \mathrm{~cm}^{-1}$, $v \mathrm{NH}=1567 \mathrm{~cm}^{-1} ;{ }^{1} \mathbf{H}$ NMR $\left(400 \mathrm{MHz}, \mathrm{CDCl}_{3}\right) ; 8.45\left(1 \mathrm{H}, \mathrm{d}, J=8.5 \mathrm{~Hz}, \operatorname{Ar}_{\mathrm{NBD}} H\right), 6.78(8 \mathrm{H}, \mathrm{m}, \operatorname{ArH})$, $6.31\left(1 \mathrm{H}, \mathrm{d}, J=8.5 \mathrm{~Hz}, \operatorname{Ar}_{\mathrm{NBD}} H\right), 4.45\left(2 \mathrm{H}, \mathrm{d}, J=13.3 \mathrm{~Hz}, \mathrm{ArCH}_{2} \mathrm{Ar}\right), 4.44(2 \mathrm{H}, \mathrm{d}, J=13.3 \mathrm{~Hz}$, $\left.\mathrm{ArCH}_{2} \mathrm{Ar}\right), 4.09\left(2 \mathrm{H}, \mathrm{t}, J=6.9 \mathrm{~Hz}, \mathrm{OCH}_{2} \mathrm{CH}_{2} \mathrm{CH}_{2} \mathrm{~N}\right), 3.83\left(8 \mathrm{H}, \mathrm{m}, \mathrm{OCH}_{2} \mathrm{CH}_{2} \mathrm{CH}_{3}, \mathrm{OCH}_{2} \mathrm{CH}_{2} \mathrm{CH}_{2} \mathrm{NH}_{2}\right.$, coincident), $3.26\left(2 \mathrm{H}, \mathrm{d}, J=13.3 \mathrm{~Hz}, \mathrm{ArCH} \mathrm{H}_{2} \mathrm{Ar}\right), 3.25\left(2 \mathrm{H}, \mathrm{d}, J=13.3 \mathrm{~Hz}, \mathrm{ArCH}_{2} \mathrm{Ar}\right), 2.37(2 \mathrm{H}, \mathrm{m}$, $\left.\mathrm{OCH}_{2} \mathrm{CH}_{2} \mathrm{CH}_{2} \mathrm{~N}\right), 1.85\left(6 \mathrm{H}, \mathrm{m}, \mathrm{OCH}_{2} \mathrm{CH}_{2} \mathrm{CH}_{3}\right), 0.90\left(9 \mathrm{H}, \mathrm{m}, \mathrm{OCH}_{2} \mathrm{CH}_{2} \mathrm{CH}_{3}\right) ;{ }^{13} \mathbf{C} \mathbf{N M R}(100 \mathrm{MHz}$; $\left.\mathrm{CDCl}_{3}\right) ; 156.1,155.9,135.9,135.8,135.7,135.6,124.4,124.1,122.8,122.7,122.6,76.8,76.6,72.5$, 29.6, 22.4, 22.3, 8.7, 8.6; M/z (ESI) Calc'd for free amine $\mathrm{C}_{46} \mathrm{H}_{55} \mathrm{~N}_{8} \mathrm{O}_{7} 831.4188$, observed 831.4189

Biological Methods. Cell Viability Studies. MTS assays were performed using a CellTiter $96^{\circledR}$ AQ ${ }_{\text {ueous }}$ Non-Radioactive Cell Proliferation Assay (Promega). All cell lines used have been described earlier. ${ }^{2}$ All cells were incubated at $37^{\circ} \mathrm{C}$. Freshly harvested CHO cells were suspended in DMEM (Invitrogen) 
with $10 \%$ Foetal Calf serum and 2mM glutamine, HL-60 cells in RPMI (Invitrogen) with 10\% Foetal Calf serum and $2 \mathrm{mM}$ glutamine, at a concentration of $1 \times 10^{5}$ cells $/ \mathrm{mL}$. $50 \mu \mathrm{L}$ of the cell solution was incubated with $30 \mu \mathrm{L}$ of each of the calixarenes 4 and 5 in buffer, at concentrations of $150 \mathrm{mM}, 15 \mathrm{mM}$, $1.5 \mathrm{mM}, 0.15 \mathrm{mM}, 0.015 \mathrm{mM}$ or with a mixture of $15 \mathrm{mM}$ calixarene 4 and increasing concentration of $\beta$ cyclodextrin. CHO cell viability was measured by MTS assay at $72 \mathrm{~h}$. HL-60 cell viability was measured by MTS assay at $84 \mathrm{~h}$.

Image acquisition. $\mathrm{CHO}$ cells were grown on coverslips overnight, incubated with NBD, $\mathbf{4}$ or $\mathbf{5}$ for different time points at $37^{\circ} \mathrm{C}$. Cells were washed three times in ice-cold PBS and either mounted on glass-slides or used for counter stain with a monoclonal antibody that binds to a receptor in the cell membrane. The immunofluorescence procedure has been described previously. ${ }^{2}$ Briefly cells were incubated with saturating amounts of antibody $\mathrm{HEK} / 1 / 85 \mathrm{a} / 7 \mathrm{a}$ for 1 hour at $4^{\circ} \mathrm{C}$, washed three times with PBS, incubated for 1 hour with a corresponding TRITC conjugated antibody, washed with PBS three times and mounted in glycerol on glass slides. Pictures were acquired using either a Zeiss Axiovison 2 fluorescence microscope or a Leica TCS SP2 UV Confocal Imaging system.

\section{Results and Discussion}

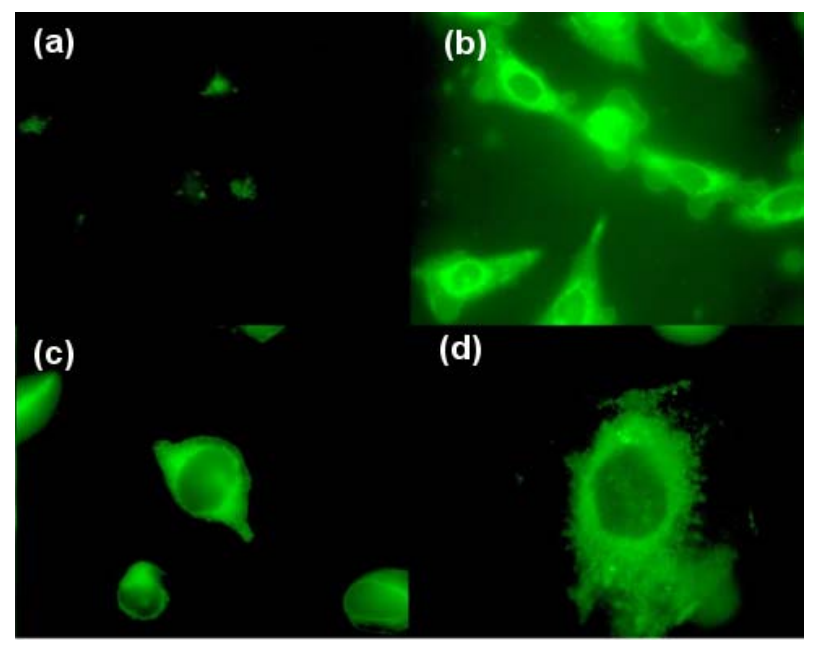

Figure S1. Images of CHO cells (a) NBD control $(500 \mathrm{mM})$ (b) after 20 minutes pre-incubation with 4 $(150 \mathrm{mM})$ (c) after 30 minutes (d) after 60 minutes. Images were acquired using a Zeiss Axiovision 2 microscope.

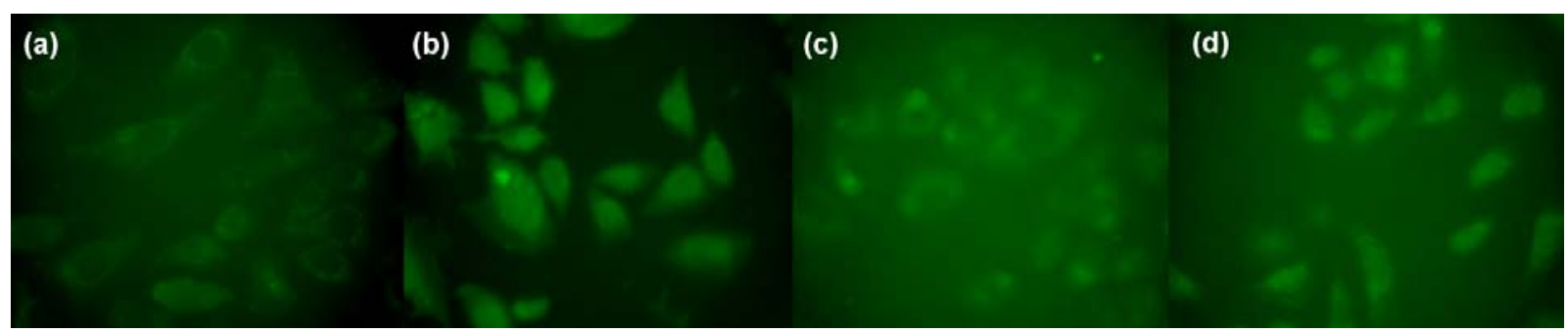

Figure S2: Control fluorescence with NBD fluorophore on its own. Images of CHO cells 1 hour after pre-incubation with inhibitors with NBD added for $10 \mathrm{~min}$ at $300 \mathrm{mM}$ concentration (a) NBD (b) NBD and filipin $(5 \mu \mathrm{g} / \mathrm{ml})(\mathrm{c}) \mathrm{NBD}$ and sucrose $(0.4 \mathrm{M})(\mathrm{d}) \mathrm{NBD}$ and $\beta$-cyclodextrin $(0.1 \mathrm{M})$ 


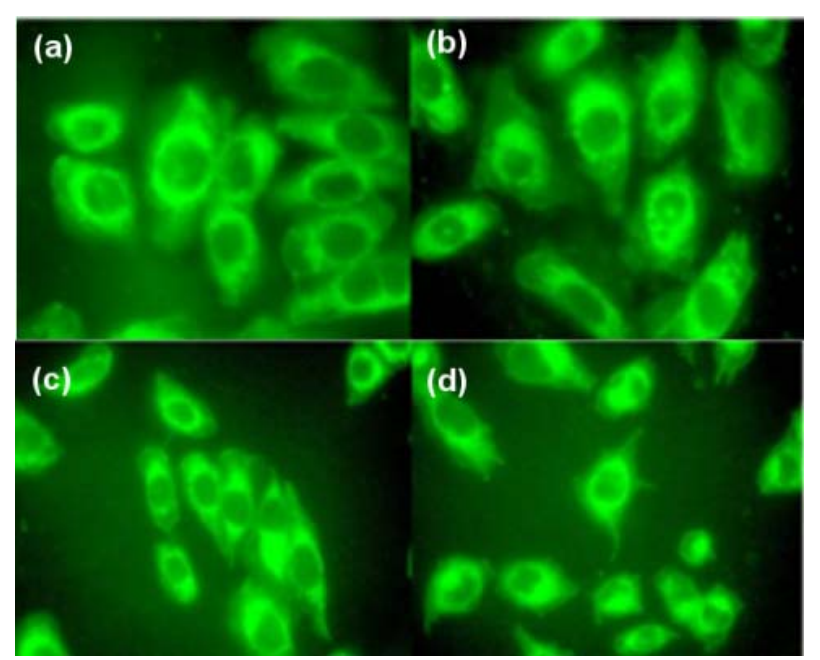

Figure S3. Images of CHO cells 1 hour after pre-incubation with inhibitors with 4 added for 10 min at $15 \mathrm{mM}$ concentration (a) 4 (b) 4 and filipin $(5 \mu \mathrm{g} / \mathrm{ml})$ (c) 4 and sucrose $(0.4 \mathrm{M})$ (d) 4 and $\beta$-cyclodextrin $(0.1 \mathrm{M})$
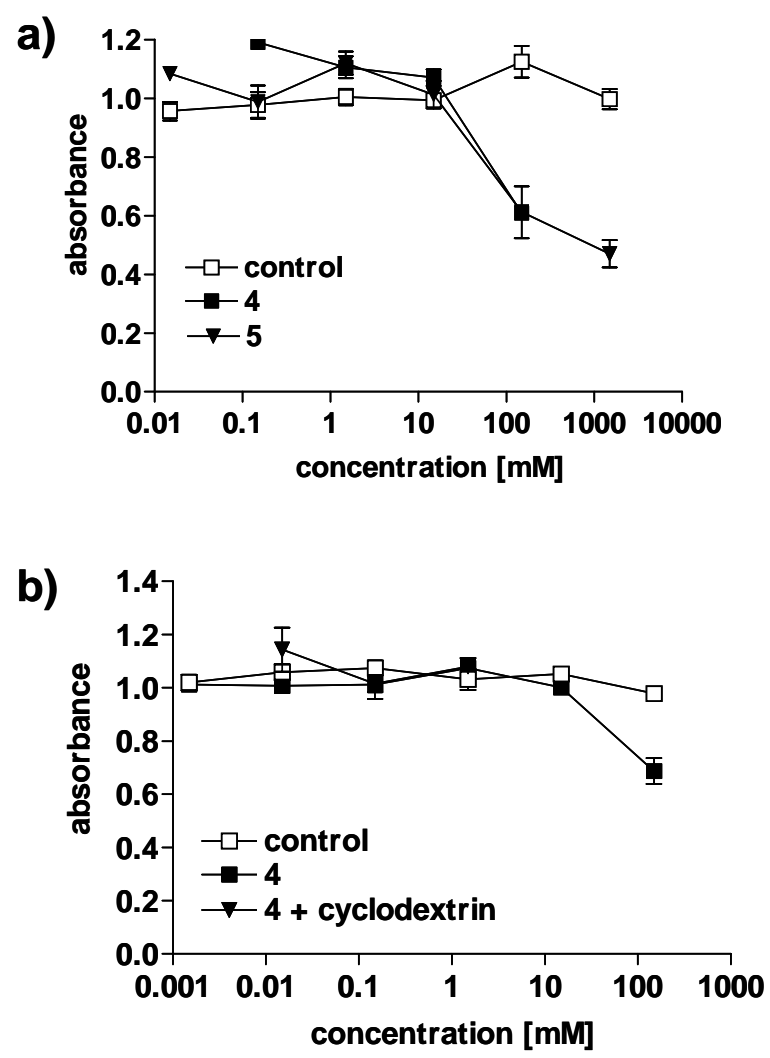

Figure S4 Representative cell viability assays (CHO cells tested for proliferation after 72 hours using an MTS assay) (a) comparison of 4 and 5 (b) comparison of $\mathbf{4 , 4}(15 \mathrm{mM})$ and increasing concentration of $\beta$-cyclodextrin. Phosphate Buffered Saline used as a control in all studies. 


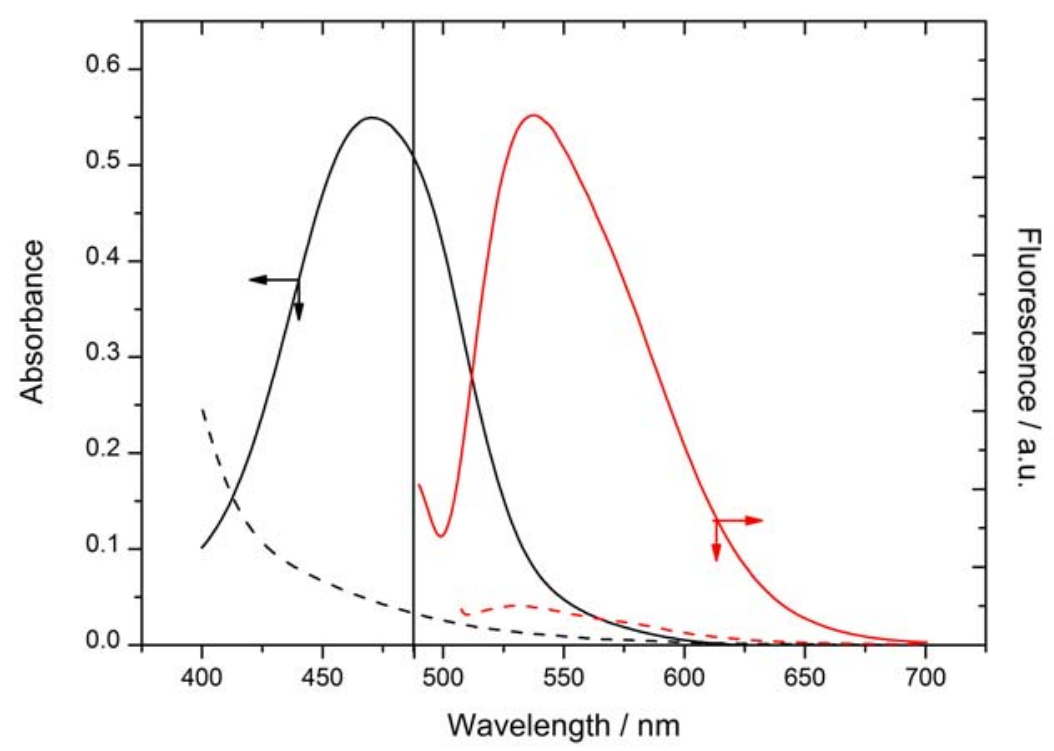

Figure S5 Absorbance spectrum of $4\left(5.12 \times 10^{-8} \mathrm{M}\right)$ [black full line] and $5\left(5.12 \times 10^{-6} \mathrm{M}\right)$ [black dotted line]. Emission spectrum of $4\left(5.12 \times 10^{-8} \mathrm{M}\right)$ [red full line] and $5\left(5.12 \times 10^{-6} \mathrm{M}\right)$ [red dotted line] following excitation at $488 \mathrm{~nm}$

\section{References}

(1) Lalor, R.; DiGesso, J. L.; Mueller, A.; Matthews, S. E. Chem. Commun. 2007, 4907-4909

(2) Mueller A., Kelly E., Strange P. G., P. Blood 2007, 99, 785-791. 